\title{
PARA UMA PROPEDÊUTICA DA SOCIOLOGIA DO TRABALHO ${ }^{1}$
}

\author{
Ana Paula Marques ${ }^{2}$
}

\begin{abstract}
RESUMO
Neste artigo pretende-se encetar uma reflexão em torno Sociologia do Trabalho e da centralidade do conceito "trabalho" nas sociedades contemporâneas. A partir da experiência de leccionação da disciplina nos últimos anos, a autora tem vindo a assumir que a Sociologia do Trabalho, antes de ser um campo disciplinar específico, é uma Sociologia. Tal pressupõe que se apresentem algumas considerações prévias e introdutórias a esta disciplina, estimulando a compreensão crítica das temáticas em torno dos fenómenos relacionados com o trabalho.

Palavras-chave: Sociologia do Trabalho; Ensino de Sociologia
\end{abstract}

\section{TOWARDS A PROPAEDEUTICS OF THE SOCIOLOGY OF WORK}

\begin{abstract}
In this paper it is intended to build a reflection on the Sociology of Work and on the centrality of the concept of "work" in contemporary societies. The experience deriving from the teaching of this discipline in the last years, allows the author to assume that the Sociology of Work, before being a specific disciplinary field, is Sociology. To reinforce this, some previous and introductory considerations to this discipline are presented, trying to stimulate a critical understanding of the issues underlying the different aspects that work and labour present to us.

Keywords: Sociology of Work; Teaching Sociology
\end{abstract}

\section{Trabalho e Sociologia}

Desde o seu início que a Sociologia se tem preocupado com a análise do trabalho e dos seus efeitos na configuração da sociedade moderna. Apesar de diversas perspectivas e concepções do mundo, os autores clássicos do pensamento sociológico, cada a um a seu modo, realçaram a importância do trabalho e das relações que se constroem a partir dele para se compreender a

\footnotetext{
${ }^{1}$ Este artigo integra parte de reflexões do Caderno de Apoio à disciplina Sociologia do Trabalho - Uma introdução à Sociologia do Trabalho (2004)

2 Professora auxiliar do Departamento de Sociologia do ICS - Universidade do Minho (e-mail: amarques@ics.uminho.pt).
} 
sociedade. Actualmente, perante as profundas transformações nos vários dominios da actividade humana, o recurso à investigação sociológica apresenta-se como um instrumento indispensável para analisar, compreender e explicar tais mudanças e seus impactos sociais.

Numa introdução à "Sociologia do Trabalho", pretende-se realçar as interrogações, inúmeras e diversas, que podem ser formuladas em torno dos fenómenos relacionados com o trabalho. Uma Sociologia do Trabalho é possível? Como os sociólogos clássicos compreenderam e estudaram o trabalho? Actualmente, qual(ais) é(são) o(s) significado(s) atribuído(s) ao trabalho? O trabalho tende a desqualificar-se, ou pelo contrário, constitui uma fonte de realização profissional? Podem os trabalhadores resistir aos processos de controlo organizacional? Em que medida as mulheres experimentam o trabatho diferentemente dos homens? Como compreender e explicar as transformações no trabalho, no emprego e no desemprego registadas nas sociedades contemporâneas? Tais interrogações são exemplificativas de um certo desenvolvimento dos principais marcos teóricos que têm vindo a balizar a discussão em torno das principais transformações no mundo do trabalho e dos processos de reestruturação que ocorrem na maioria dos países ocidentais.

Uma das estratégias usadas para estimular o debate e a participação por parte dos alunos consiste em assumir que a Sociologia do Trabalho, antes de ser um campo disciplinar específico, é uma Sociologia. Tal pressupõe que se apresentem algumas considerações prévias e introdutórias a esta disciplina.

Antes de mais, importa não esquecer a relevância do espírito crítico e a especificidade do conhecimento sociológico na análise dos fenómenos complexos do trabalho. Trata-se de precaver os alunos no sentido das limitações presentes quando se adopta um estilo pragmatista, que, no extremo, perspectiva apenas a resolução acrítica e conformista dos diversos problemas relativos à produtividade, à motivação e satisfação profissional, ao controlo e racionalização dos processos de organização de trabalho, entre outros aspectos, alheando-se quer das suas dimensões políticas, quer do poder diferenciado dos actores sociais envolvidos. Porém, quando se envereda por um hipercriticismo como atitude privilegiada, secundarizando o trabalho de campo, a investigação in locus, a utilização de métodos e técnicas disponíveis na Sociologia, restringe-se também o campo de "visibilidade" de novas situações de pesquisa, que poderão constituir fonte de desafios intelectuais e de criatividade sociológica (Pinto, 1994).

O repto de "regressarmos aos clássicos", como sugere Castillo (1998: 90), constitui um excelente exercício para perceber que, ao contrário do divulgado na "literatura de aeroporto", muitos dos fenómenos que pensamos ser produto das "novas tecnologias", ou de "novas formas de organiza- 
ção do trabalho", não são tão novos como isso; apresentam-se, hoje, certamente mais complexos, exigindo o contributo das diversas ciências sociais e dos seus instrumentos analiticos. Nesta partilha de conhecimentos e de informações substantivas, será possivel ir além da "descoberta" dos fenómenos de trabalho que perpassam as sociedades contemporâneas para se avançar nos seus factores de compreensão e de explicação.

Tal passa por assumir uma sociologia em sentido lato que remete necessariamente para os quadros teóricos dominantes, para a neutralidade axiológica através da deontologia do exercício profissional (embora com constrangimentos sociais e exigências contextuais), para o património metodológico disponível. Assim, os obstáculos que se insinuam de forma manifesta, embora muitas vezes de modo não implícito, nos processos de intelecção da investigação, poderão ser objecto de atenção e como tal de análise, sendo mais facilmente controlados. Falamos, em concreto, de observações e análises eivadas de preconceitos, particularismos, naturalizações dos fenómenos em estudo. Claro que a Sociologia já avançou nas estratégias a adoptar para contrariar e superar tais "debilidades" que fazem dela sempre "suspeita" de dogmatismos, ideologismos, sociologismo e outras expressões de idêntico valor semântico.

Justamente, a especificidade do conhecimento sociológico consiste na capacidade de se desenvolver esquemas de análise relacionais, contextualizadas, verificáveis e empiricamente refutáveis. Ou seja, a ciência, enquanto processo contínuo de construção e posterior validação (condicionada e muitas vezes provisória) de conhecimentos, visa a transformação de problemas sociais (manifestações empíricas a nível colectivo, como por exemplo a observação de comportamentos de insatisfação tipificados em diversas baixas médicas, conflitos, baixa produtividade, etc.) em problemas sociológicos (motivações no e do trabalho), utilizando as condições conceptuais (teorias, princípios e hipóteses) e operativas existentes. No âmbito da sociologia do trabalho, os fenómenos de trabalho são "fenómenos sociais totais", no sentido em que M. Mauss emprega este termo no seu Ensaio Sobre o Dom (1925).

É claro que estas observações não são isentas de dificuldades na afirmação da pertinência de uma Sociologia do Trabalho. Ao se incentivar a interdisciplinariedade e libertar a "imaginação sociológica" assume-se que se está perante fenómenos que extravasam as fronteiras fixas e definidas de uma vez por todas. Igualmente, o facto de as ciências serem fruto de "condições histórico-sociais" (Pinto, 1991) recoloca questões que saem do estrito campo científico e intelectual (incluindo as condições institucionais de produção científica, as condições teóricas, nomeadamente os paradigmas e as técnicas e os modelos de intervenção social). A procura diferenciada de produtos 
científicos, por um lado, e a circulação/apropriação social de conhecimentos, por outro, remetem-nos para as condições sociais globais de uma dada sociedade num determinado momento histórico. As relações de força entre o campo científico e as condições económicas, jurídico-políticas e ideológico-culturais dominantes são também parte integrante do que se produz cientificamente, da "delimitação" de certos fenómenos sociais ou da "opacidade" de outros, da eleição de certos produtos e da secundarização de outros.

\subsection{Trabalho, conceito não exclusivo da sociologia}

Parte-se de uma posição relativamente consensual no que diz respeito ao facto de o trabalho se constituir num traço específico da espécie humana, numa dimensão estruturante e modal da vida social. Contudo, são alguns os problemas que se colocam quando está em causa a sua definição e a afirmação de fronteiras distintas de outras abordagens científicas, como sejam as elaboradas no quadro de outras ciências sociais, como por exemplo, Economia, Direito, Psicologia Social, Gestão.

Um desses problemas prende-se com a vastidão geralmente associada à definição do trabalho e consequentemente à sua delimitação científica. Associada ao trabalho, proliferam vocábulos e expressões próximas, relativamente equivalentes, outras remetendo para quadros de pensamento diferenciados. Eis alguns exemplos de proximidades, mas também de distâncias conceptuais: trabalho $e$ actividade, trabalho e emprego, trabalho e desemprego, não-trabalho $e$ inactividade.

Com efeito, se trabalho se refere a uma actividade que pode ser ou não remunerada, produtiva ou não produtiva no sentido económico restrito Smith ([1776]1999) -, o emprego pressupõe sempre uma actividade remunerada articulada com as condições que definem a utilização da mão-de-obra (qualificação profissional, reforma, subsídio de doença, etc.), ou seja, de acordo com um certo quadro jurídico-legal vigente. Nesse sentido, ter um trabalho pode não ser incompatível com o estatuto de desempregado, assim como o não-trabalho não tem necessariamente o mesmo significado de desemprego, já que pode representar diversas situações, desde inactividade (constrangida ou voluntária) à frequência de acções de formação.

Igualmente, o conceito de trabalho pode ser utilizado para definir aspectos quantificáveis (e.g. nível salarial, rendimento, grau de destreza intelectual/manual) como também aspectos não materiais e não quantificáveis (e.g. auto-realização profissional, prestígio e status, atitudes e representações simbólicas). Em termos sociológicos, definir trabalho implica que se mobilizem diversas variáveis, como sejam nível social, idade, localização geográfica, esco- 
laridade, entre outras. Por outro lado, o tipo de trabalho desempenhado por um grupo social, a sua situação profissional e condição perante o trabalho, podem ser utilizadas como variáveis independentes na explicação de determinados padrões de comportamentos e atitudes face ao consumo, à cultura, ao lazer, à orientação político-ideológica, entre outros aspectos.

Uma outra fonte de ambiguidade semântica consiste no facto de o trabalho constituir uma realidade variável e relativa aos contextos e aos grupos sociais a que diz respeito. Não constitui uma realidade uniforme no tempo e no espaço, tendo apresentado diferentes significados ao longo da história. Trata-se portanto de um conceito problemático que exprime uma realidade mutável, pelo que assume valores e representações diferentes consoante as épocas históricas, as representações e os grupos sociais implicados. Aprofundaremos de seguida este ponto.

\subsection{Evolução do conceito "trabalho" e suas explicações dominantes}

Com base nas ideologias dominantes sobre o trabalho ao longo da história até aos nossos dias (e.g. Gamst, 1995, Costa, 1992), iremos seguir de perto a proposta de Moreno (1999), que identifica o predomínio de explicações extra-societárias durante as principais épocas históricas até ao princípio do século XIX, por um lado, e, por outro, as explicações societárias, sendo o seu início identificado com o contributo de K. Marx ([1867] 1974).

\subsubsection{Explicaçôes de cariz extra-societária}

Uma primeira explicação de cariz extra-societária designa-se de "Divinização das relações e valores sociais" (Moreno, 1999). A esfera do sagrado é a dos absolutos sociais como assinala Durkheim ([1912] 1960]. Durante muitos séculos esteve ocupada pela associação estreita entre a Religião e o Estado. Concretizada em cada formação social e em cada época por crenças, valores, rituais e práticas sociais, esta fusão sacralizada do religioso e do politico - que na Idade Média se chamava de aliança entre Trono e Altar (pelo menos em Espanha) - garantiu a ordem económico-social e sua reprodução para além das descontinuidades dos modos de produção. Os altos funcionários e os sacerdotes apresentavam-se como os mandatários das forças divinas, de Deus, possuindo a explicação para o mundo e para a ordem social de cada sociedade, legitimando esta e simbolicamente representada por um soberano que deve velar pela sua perpetuação.

As relações sociais desiguais de sexo, de etnia e de estatutos sociais eram atribuídas à ordem do mundo e das coisas, estabelecidas de uma vez por 
todas por vontade divina. Nesta extensa época histórica, o trabalho constitui-se como a actividade obrigatória para muitos colectivos identitários subalternos, tais como: $i$ ) as mulheres com o trabalho doméstico e em trabalhos com muito baixo prestígio social; ii) os povos dominados que tinham de trabalhar para garantir a sua subsistência, para pagar impostos ou tributos ao dominador; $\mathrm{iii}$ ) as populações oprimidas, que segundo as épocas, foram escravos, servos ou trabalhadores "livres". O trabalho era entendido sobretudo como trabalho manual e considerado como um elemento de tortura. Do latim, trabalhar significava precisamente tripaliare que pressupunha torturar com o tripaliu, que resulta da palavra tripalis, derivada de tres + palus, ou seja, um instrumento de tortura constituído por três paus. Trabalhar significava igualmente a pena a cumprir pelos actos e pecados contrários à divindade.

Só quem participava de algum modo no sacro religioso ou sacro estatal poderia escapar a essa tortura do trabalho. Era o caso dos sacerdotes, curandeiros, astrólogos e outros funcionários dedicados a reverenciar a divindade ou divindades, como também os governantes, escribas, juristas, guerreiros e todos os que contribuíam para a gestão do sacro Estado. Uns e outros poderiam dedicar-se à direcção de assuntos públicos e proporcionar a protecção sobrenatural da sociedade que era mantida pelo trabalho pela maioria da população e cujos resultados chegavam na forma de tributos, impostos ou dízimos. A ideologia da ordem social, regulada por preceitos divinos e pela ideia de "serviço" à comunidade e mesmo de "sacrifício" pela comunidade, por parte das classes dominantes, constituía a base do consentimento social para a dominação, percebida não como tal, mas como garantia da reprodução da ordem social e sobrenatural.

A "naturalização das relações e valores sociais" (Moreno, 1999) instituise, progressivamente, como explicação alternativa àquela. Com efeito, a introdução da doutrina calvinista e das ideias protestantes marca uma importante alteração na ideologia sobre o trabalho: este não representa apenas uma lembrança do estigma do pecado original, nem um meio heróico de santificação pessoal para algumas das minorias medievais, mas sobretudo o êxito nas actividades económicas que pressuponha também um sinal de predestinação, de ter sido favorecido pelo Absoluto. Weber ([1905] 2001), refere-se a esta inflexão ideológica como estando estreitamente ligada ao desenvolvimento do capitalismo, constituindo a base para uma ética puritana do trabalho: o trabalho já não é propriamente um castigo sobrenatural, mas um imperativo ético ditado pela divindade.

Timidamente desde o Renascimento e já de forma acentuada no Iluminismo, no Ocidente, o sacro religioso ou a centralidade do sagrado foi sendo substituída pela Razão como Absoluto, ou seja, pela lógica racionalista 
europeia, mantendo-se como sacro o Estado progressivamente legitimado pela racionalidade em vez da religião. Racionalizar, que significa "civilizar", converte-se agora na justificação ideológica que legitima a dominação europeia sobre os outros povos do mundo. Civilizar os "selvagens" constitui uma legitimação equivalente da outrora assente na evangelização dos "infiéis". Por outro lado, sendo definidos os homens como detentores de maior racionalidade por comparação com as mulheres - porque estas eram caracterizadas por mais instáveis emocionalmente -, o masculino continua a afirmar-se como superior ao feminino.

A ideologia legitimadora das desigualdades assenta agora na ordem natural das coisas: as raças inferiores e o sexo inferior estão destinados por natureza ao trabalho. Daí a permanência da escravidão, ou então a exclusão não só económica, mas social e política de todos os povos não ocidentais e de todas as mulheres. Só os dominantes europeus (e também os norte americanos de origem europeia) e os homens são chamados a actividades significativamente não qualificadas de "trabalho" sempre que pertençam às elites dominantes: governo, exército, sacerdócio, profissões liberais, comércio. E só os europeus varões que não fazem parte destas ditas elites podem ter outros trabalhos mais modestos - estes sim designados por "trabalho" como o caminho para viver cristãmente as penalidades terrenas, cumprindo assim a sua função na vida. Só para os europeus homens de certas classes socais era aplicável e funcional a ética puritana sobre o trabalho.

\subsubsection{Explicações de cariz societário}

Seria apenas no século XIX, mediante sobretudo as teses de K. Marx ([1867] 1974), que se apresentaria pela primeira vez uma distinção entre trabalho e "trabalho alienado", configurando um outro tipo de explicação "Legitimação pelo modo de produção de cada sociedade" (Moreno, 1999). A conceptualização do trabalho realiza-se assim com base na estrutura de cada sociedade, ou mais concretamente, do modo de produção dominante e não nas esferas extra-sociais sejam sobrenaturais ou naturais. As relações sociais de produção assimétricas e de dominação fazem com que o trabalho perca o seu valor fundamental que consiste na articulação entre a vida material e a actividade intelectual; valor que só será possível recuperar numa sociedade sem classes em que cada um terá o trabalho adequado a si.

Apesar das evidentes insuficiências da análise marxista quanto às relações sociais de sexo e relações inter-étnicas e nacionalistas, as implicações deste pensamento foram muitos importantes. Tanto o marxismo como as correntes do denominado socialismo utópico foram importantes para a 
dignificação do trabalho aos olhos de quem teria de sofrê-lo, sem o qual não seria possivel legitimar as formas e as condições em que este se exercia. E neste caso, existem tantas semelhanças como diferenças em relação à ética puritana do trabalho. No combate às ideias liberais e socialistas, já no século XIX, a Igreja começa a preocupar-se com o "mundo do trabalho", exaltando, no seu discurso, a importância do trabalho como dever cristão.

Hoje, perante as transformações registadas na economia capitalista, a raiz da legitimação assenta no mercado, ocupando este o lugar central do sagrado de outrora - "sacralização do mercado". (Moreno, 1999). Quando o trabalho não se integra no mercado, quer dizer, quando não funciona como mercadoria, com valor de troca, está desvalorizado socialmente ou não se percebe sequer a sua existência: assim ocorre com o trabalho das "domésticas" que não trabalham, apenas fazem as suas actividades de casa, ou com o trabalho que realizamos para nós mesmo que possui, quando muito, um grande valor de uso. E é com esta mesma lógica que se interpreta a situação dos desempregados de longa duração, dos jovens sem emprego, dos inactivos, que são socialmente marginalizados porque estão excluídos do mercado de trabalho.

As transformações estruturais na natureza do capital e na produção que caracterizam esta nova fase de desenvolvimento do capitalismo parecem inaugurar uma reconversão ideológica para legitimar o modelo actual de mundialização do mercado de capitais, de tecnologia e produtos, da força de trabalho. Tal reconversão ideológica assenta no estilhaçamento progressivo, de forma objectiva e subtil, das conquistas sociais dos trabalhadores nas últimas décadas. De forma objectiva, trata-se das alterações no corpus legal de direitos reconhecidos em relação ao trabalho e as obrigações do Estado face aos trabalhadores. De forma subtil, trata-se da destruição de culturas de trabatho que os diversos colectivos modelaram como resultado de suas experiências em processo de trabalhos específicos com base em relações concretas de produção.

Como temos vindo a argumentar, o trabalho enquanto traço modal e específico da espécie humana, assume contornos e significados diferenciados ao longo da história, consoante os contextos político, económico, social e ideológicos preponderantes.

\section{Sociologia do Trabalho}

\subsection{Uma definição possível?}

Depois de expostas, ainda que de modo breve, algumas das razões que 
estão na base da dificuldade de definição dos contornos deste conceito, ao mesmo tempo estável e em permanente transformação, convém recuperar os esforços e os ensaios realizados nesse sentido.

Antes de mais, importa preservar a abrangência do objecto científico de estudo da Sociologia do Trabalho, muito em particular na análise das realidades actuais do mundo do trabalho, sugerida por G. Friedmann (1973, vol.1: 37):

"A sociologia do trabalho deve ser considerada em sua vasta extensão, como o estudo, nos diversos aspectos, de todas as colectividades humanas que se constituem graças ao trabalho."

Em seguida, realçar a dimensão problemática associada aos fenómenos de trabalho, seguindo de perto a posição de P. Rolle (1978: 9):

"O trabalho representa simultaneamente uma realidade incontestável para o indivíduo que lhe está sujẹito e uma noção confusa que só se precisa no interior de um conjunto de relações"

Por fim, assumir e preservar a pertinência de uma sociologia especializada, tal como defende J. Freire (1993: 11):

"A sociologia do trabalho è (...) uma sociologia que se dedica, diferentemente de outras, ao estudo particular dos fenómenos ligados ao trabalho".

Ou, como nos alicia J. Castillo (1998: 134), com o seu olhar optimista e orientador de caminhos dos sociólogos do trabalho, que não abdica de convocar os referentes teóricos em torno dos conceitos de trabalho e emprego:

"A nossa reflexão actual continua um caminho iniciado por meio de uma consideração global, destinada a situar os pontos de vista que nos ajudem a distinguir para onde vai a sociologia do trabalho (...). Nenhum teórico ou investigador no seu perfeito juízo duvida hoje, no nosso campo, de que a redutora, escorregadia e multiforme (ou disforme...) noção ou descrição de 'emprego', para já não falarmos desse trabalho adjectivado a dobrar como formalmente assalariado, constitua um obstáculo quando queremos pensar o trabalho, os trabalhos dos nossos dias, trabalhos esses que se tornam cada vez mais imperceptiveis para um olhar que não saiba ser, ele próprio, complexo, inquirindo para além desse esplendor de fogo-de-artificio fabricado sob o rótulo de "o fim da sociedade do trabalho"'.

O caminho a seguir é portanto "buscar o trabalho", porque, sem ele, a 
"sociologia do trabalho perde o rumo ou afunda-se em debates diletantes que pouco ou nada têm que ver com as mulheres e os homens reais (que, de facto, trabalham) (Castillo, 1998: 150). Com os contributos da teoria e da história, diz-nos o autor que "o primeiro passo é redescobrir o trabalho. E, com ele, ao mesmo tempo, uma sociologia que necessita urgentemente de novas linhas de pensamento para compreender as sociedades complexas dos nossos dias" (ibidem: 152).

\subsection{Delimitação do objecto científico}

De tudo o que foi dito, a Sociologia do Trabalho apresenta diferentes níveis analíticos, ou, se o preferirmos, diferentes olhares sobre a realidade do trabalho. Por isso, sempre que esteja em causa analisar um determinado fenómeno relacionado com o trabalho, poder-se-á optar por diferentes enfoques de análise, tal como nos sugere J. Freire (1993: 21-22), de forma articulada e interdependente.

1.Diferentes situações de trabalho, definidas por uma arquitectura técnicoorganizacional, tais como equipamentos produtivos, modalidades de organização dos espaços e tempos dos trabalhadores, dos produtos, dos clientes, dos fornecedores, etc. dos saberes e normas de funcionamento. Ou seja, tudo o que é considerado necessário para que a empresa funcione e que prossiga os seus objectivos $\left(\mathrm{n}^{\circ} \mathrm{de}\right.$ trabalhadores, ritmos, horários, salários, etc.)

2.Relações de trabalho no sentido de se integrar a constante produção e reprodução de relações sociais por parte dos trabalhadores adscritos às diferentes situações de trabalho. A importância destas relações de trabalho pressupõe alguma durabilidade das trocas entre pessoas, cuja materialidade de relações se objectiva nas várias formas de cooperação e/ ou conflito, formas de autoridade e/ou controlo, formas de participação e/ou passividade, formas de centralização de competências e/ ou delegação, entre outras. Tratam-se sobretudo de dimensões relacionáveis, observáveis e duráveis e que produzem efeitos específicos. A durabilidade das trocas/relações de trabalho, constituindo uma dimensão relacional no tempo e no espaço, permitem pela sua consistência ou não, a produção de determinados efeitos. Se fisicamente não existirem espaços propícios ao convívio laboral, não se pode dizer que existem relações de trabalho num espaço formal, podendo estas estar confinadas a um espaço informal (como por exemplo casas-de-banho, salas de convivio, etc.).

3.Representações mentais, incluindo todos os significados e símbolos produzidos pelos actores intervenientes, em contextos de trabalho. Esta dimensão de análise, muitas vezes negligenciada, apresenta-se indissociável daqueles dois níveis precedentes. Qualquer que seja o fenómeno em análise, deve sempre contemplar a subjectividade implícita nas práticas (os valores, visões do mundo, etc.). As representações sociais são conceitos que servem para definir situações nem sempre visiveis 
pelas pessoas. Cabe por isso à sociologia analisar esta dimensão simbólica de sentidos e valores produzidos inconscientemente pelos actores sociais e que surgem incorporados em disposições diversas.

De certa forma, a análise sociológica implica perceber que o trabalho é uma realidade objectiva e diferenciada de país para país, de cultura para cultura, tal como vimos. Mas, implica também perceber que o trabalho tem uma importância fundamental na moldagem de valores, atitude e comportamentos dos actores sociais, pelo que constitui, além da família e da escola, um espaço de socialização e de aprendizagem importantes. Tal pode contribuir para uma reprodução da "lógica classista" (Pinto, 1991) preponderante nas sociedades capitalistas, como pode potenciar rupturas, que quase sempre são acompanhadas por rupturas nas outras instâncias de socialização e de aprendizagem, nas trajectórias e na antecipação dos projectos.

\section{Trabalho do passado, trabalho do futuro: para uma renovação da sociologia do trabalho}

Ao contrário dos que defendem a "crise" da própria Sociologia do Trabalho, a partir da perda da centralidade da categoria do "operário-massa", expressão de uma realidade relativamente homogénea e comum a muitos dos trabalhadores assalariados de uma época em que dominava a indústria e do seu paradigma de eleição - o determinismo tecnológico (Maurice, 1985: 250), Castillo (1998) propõe um olhar sobre o passado e o futuro do trabalho, perspectivando uma sociologia capaz de se renovar.

Há, porém, outras razões que permitem explicar este estado de coisas. Uma delas prende-se com as profundas alterações no trabalho ao nivel da sua prática, estatuto e natureza de relações com a empresa, que pressupõem novos ritmos de trabalho, novas organizações e valores sociais. Transformado nas suas formas, o trabalho evolui igualmente no seu conteúdo e na sua significação social. Com efeito, os argumentos desenvolvidos sobre o futuro ou o fim do trabalho assentam, pelo menos, em duas ideias interdependentes: a alegada supressão material do trabalho e a transformação dos seus significados para as pessoas. Estes debates assumem, desde logo, que tanto o trabalho como o seu contexto evoluíram e contribuíram para aumentar a complexidade das sociedades de hoje. Pensámos que e a diversidade de posições permite, desde logo, contrariar a ideia de que se está perante tendências uniformes e inelutáveis relativas a esta temática. Por outro lado, orienta-nos no trabalho de argumentação.

Importa questionar o que se entende por "trabalho do futuro", tendo 
presente que os conhecimentos acumulados, fruto de diversas investigações realizadas, nos dizem, paradoxalmente, quanto de passado e presente têm ainda o exercício das actividades profissionais para muitos dos grupos sociais. Os exemplos podem vir tanto do número de acidentes de trabalho que, por exemplo, faz de Portugal um dos países onde mais mortes acontecem no sector da construção civil, por exemplo (Pinto, 1999), como dos ritmos intensos de trabalho que são denunciados por jovens qualificados que, em início de uma carreira profissional, chegam a trabalhar mais de 10 horas diárias (Marques, 2003). Além do controlo sofisticado das pausas e tempos dos trabalhadores, fala-se da determinação do número de idas à casa de banho ou da assinatura digital na entrada da organização. Quais são os critérios que permitem identificar as características do futuro do trabalho? A este propósito, parece que há muitas confusões e precipitações, querendo ver-se realidades novas em quadros organizacionais e de pensamento oriundos de lógicas de racionalização bem conhecidas e implantadas na malha sócioeconómica.

Por outro lado, estas questões estão dominadas, nos seus efeitos sociais, por um sentido comum ideológico de que o futuro do trabalho é obscuro e sobretudo incerto (se bem que para muitos possa já ter desaparecido!) pelo que se cultiva um certo "caldo de justificação" de políticas económicas, laborais, industriais, educativas, formativas, entre outras, que vão modelando não só as condições de vida como as perspectivas e as visões do mundo. Tais justificações têm um outro efeito, embora implícito, mas eficaz, de tornar desnecessária a argumentação das políticas que passam a ser "opções obrigatórias" e, por isso, inevitáveis ou indiscutiveis perante os trabalhadores, os sindicatos, ou a sociedade em geral.

O que se pode fazer para romper com este "pensamento único", com a supremacia do económico sobre o social, do lucrativo sobre a qualidade e bem-estar das pessoas? O caminho passará certamente por vitalizar e aumentar a capacidade de produção de conhecimento por parte da Sociologia do Trabalho. O que isso significa?

Incentivar a interdisciplinaridade efectiva que pressupõe, além de uma declaração de intervenção de outros campos disciplinares, a utilização dos diversos enfoques no aumento da capacidade de discernimento da Sociologia do Trabalho. Quer dizer que importa que se seja historiador, ergónomo, geógrafo, psicólogo social, economista, entre outras áreas do saber.

Fazer investigação concreta, partir para o terreno e analisar as transformações em cursos de forma substantiva.

Incentivar a prática da validação de resultados, pelo confronto empírico, sendo assim que se contribui para a robustez e fecundidade das teorias. 
Com efeito, mesmo que se verifiquem importantes transformações na natureza e conteúdo do trabalho, é inquestionável que este se apresente ainda, em (des)articulação com outros valores concorrentes, como central e estruturante das relações sociais, dos tempos sociais (tempo de trabalho e de não trabalho - lógica profissional e pessoal) e dos ritmos biológicos (idade para vida activa, para reforma, etc.) na contemporaneidade. $O$ trabalho assume ainda significados diversificados consoante os grupos (étnicos, de género, etc.), os estatutos, as localizações, os contextos profissionais e outros. Embora o tempo de lazer tenha vindo a ganhar terreno, o tempo de trabalho persiste na estruturação dos tempos sociais, impondo a sua lógica ao tempo de não-trabalho.

Evidentemente que a crise económica da década de setenta (particularmente associada ao choque petrolífero), as reestruturações produtivas iniciadas nos anos oitenta e a aceleração da globalização da economia nos anos noventa, no contexto de um neoliberalismo como configuração ideológica dominante, intensificaram ainda mais estas discussões ou controvérsias, contribuindo para dar visibilidade a uma actualização da relação trabalho e emprego.

\section{Bibliografia}

Bidet, J. e Texier, J. (dir.) (1995), La Crise du travail, Paris, PUF.

Castels, R. (1995), Les métamorphoses de la question sociale. Une chronique du salariat, Paris, Fayard

Castillo, J. José (1998), "Em busca do trabalho perdido (e de uma sociologia capaz de o encontrar...), I. Kovács e J. Castillo, Novos modelos de produção: trabalho e pessoas, Oeiras, Celta Editora, pp. 131-152

Durkheim, E. ([1912] 1960) Les formes élémentaires de la vie religieuse. Le système totémique en Australie, Paris, PUF.

Freire, J.(1993), Sociologia do Trabalho: uma introdução, Porto, Ed. Afrontamento, pp. 11 48

Friedmann, G. ([1964] 1983), O trabalho em migalhas: especialização e lazeres, S. Paulo, Editora Perspectiva (trad. J. Guinsburg)

Friedmann, G. (1981), O Futuro do Trabalho Humano, Lisboa, Moraes Editores

Friedmann, G. e Naville, P. (dir.), (1973), Tratado de Sociologia do Trabalho, Vol. I e II, São Paulo, Cultrix, (Traité de Sociologie du Travail, 1962)

Gamst, Frederick, C. (éd.) (1995), Meanings of work. Considerations for the twenty-first century, New York, State University of New York Press.

Marques, A. P. (2003), "Outras Transições? Configurações e problemáticas de socialização juvenil", Cadernos do Noroeste, Série Sociologia n5, Vol. 21 (1-2), Braga, Universidade do Minho, pp. 141-161.

Marx, K. ([1867] 1974), O Capital, I e II, Lisboa, Delfos.

Maurice, M. (1985), "O determinismo tecnológico na sociologia do trabalho (1955. 
1990): uma alteração de paradigma?", D. Pimentel et al. (org.) Sociologia do Trabalho, Lisboa, A Regra do Jogo, pp. 231-254.

Méda, D. (1995), Le travail. Une valeur en voie de disparition, Paris, Aubier.

Moreno, Isidoro (1999), "Globalización, ideologías sobre el trabajo y culturas del trabajo", Areas, $\mathrm{n}^{\circ} 19$, pp. 17-34.

Paugam, S. (2000), Le salarié de la précarité, Paris, PUF.

Pinto, J. M. (1994), Propostas para o ensino das Ciências Sociais, Porto Afrontamento, pp. $29-42$.

Pinto, J. M. (1991), "Escolarização, relação com o trabalho e práticas sociais", Stephen R.

Stoer (org.) Educação, Ciências Sociais e Realidade Portuguesa. Uma abordagem pluridisciplinar, Porto, Edições Afrontamento, pp. 15-32.

Rolle, P. (1978), Introdução à Sociologia do trabalho, Lisboa, A Regra do Jogo.

Smith, A. ([1776]1999), Inquérito sobre a natureza e as causas da riqueza das Nações, Lisboa, F. Calouste Gulbenkian (trad. vários)

Silva e Costa, M. (1992), "Trabalho, sua evolução e a integração do trabalhador", Cadernos do Noroeste, vol. 5 (1-2), 57-76

Watson, T. (1987), Sociology, Work and Industry, London, Routledge

Weber, M. ([1905] 2001), A ética protestante e o espirito do capitalismo, Lisboa, Ed. Presença (trad. Ana Falcão Basto e Luís Leitão) 